\title{
The Digestive Tract Injury Secondary to Abdominal Blunt: Diagnosis and Management in Teaching Hospital of Kara (Togo)
}

\author{
Dossouvi Tamegnon ${ }^{1 *}$, Amouzou Efoé-Ga' ${ }^{1}$, Amavi Ayi ${ }^{2}$, Dagbe Massaga ${ }^{3}$, Alassani Fousseni ${ }^{2}$, Tchangaï Boyodi ${ }^{2}$, \\ Kassegne Iroukora ${ }^{1}$ and Dosseh David ${ }^{2}$
}

${ }^{1}$ Department of general surgery, CHU Kara, Togo

${ }^{2}$ Department of general surgery, CHU Sylvanus Olympio de Lomé, Togo

${ }^{3}$ Department of radiology, CHU Kara, Togo

Received: January 02, 2019; Published: February 11, 2019

*Corresponding author: DossouvI Tamegnon, Department of general surgery, CHU Kara, Togo, West Africa

\begin{abstract}
Objective: Report our experience of management of bowel injury after abdominal blunt in teaching hospital of Kara (Togo)

Methodology: It's a retrospective and descriptive study which concerned the patients operated for bowels injury secondary to abdominal blunt in department of general surgery from $1^{\text {st }}$ January 2012 to $30^{\text {th }}$ April 2018. We have studied the etiologies and mechanism, time of admission at hospital, clinic and paraclinical data, treatment and outcomes.

Results: Seventeen patients have registered among which we have 16 men and one woman. The mean age is 28 years old with extremes ranging from 9 to 58 years old. The causes are traffic accident in 15 cases, sports accident in two cases and intentional injury in one case. The admission period is less than 6 hours in 15 cases and greater than 6 hours in two cases. Six patients had presented generalized abdominal defense while eleven patients had localized abdominal defense. The abdominal X-ray performed in fifteen patients had revealed pneumoperitoneum in six cases. The ultrasound revealed hemoperitoneum in two cases and bladder perforation in one case. The computed tomography performed in one case showed hemoperitoneum. All the patients had undergone laparotomy. The lesions were localized on the jejunum in 14 cases, on stomach in one case, sigmoid colon in one case and cecum in one case. The main surgical acts performed were: suture-excision of jejunum in 13 cases and stomach in one case; resection-anastomosis of jejunum in one case; reperitonization of sigmoid colon in one case and cecostomy in one case. Three cases of death were noted due to septic shock.
\end{abstract}

Conclusion: The bowel injury is rare, but the diagnosis is difficult and done later because of the poverty of the early signs, causing a delay of the management increasing morbimortality's.

Keywords: Abdominal Blunt; Posttraumatic Bowels; Radiography; Leucocytosis; Laparotomy; General Anesthesia; Banditry; Lesions; Intestinal Perforation; Organ Perforation.

\section{Introduction}

The abdominal blunt is a common emergency. They occur most often in a context of polytrauma and regularly cause damage to the full intraabdominal organs with frequency of spleen and liver. Bowels injuries are rare. Their diagnosis is difficult and later because of the early poor symptomatology, leading to delayed management with consequent high morbidity and mortality. The aim of our study is to report our experience of the management of posttraumatic bowels injuries at Kara University Hospital (Togo).

\section{Methodology}

It is a retrospective and descriptive study, concerning patients operated for bowel injury following an abdominal blunt, in the department of general surgery at Kara University center (Togo) from 1st January 2012 to 30th April 2018.We have studied the etiologies and mechanism, time of admission at hospital, clinic and paraclinical data, treatment and outcomes.

\section{Results}

We have registered 17 patients, of whom 16 were male and one female with a sex ratio $(\mathrm{F} / \mathrm{H})$ of 0.06 .

The average age was 28 years with extremes ranging from 09 to 58 years. Patients had different profession dominated by the liberal profession (Table 1). Etiologies were represented by traffic accidents in 12 cases, sport accident in one case and voluntary injury in one case. The admission period was six hours 
in seven cases; six to twenty-four hours in nine cases and more than forty-eight hours in one case. The admission period was 6 hours in 7 cases; 6 to 24 hours in 9 cases and more than 48 hours in one case.

Table 1: Repartition of patients according to their profession.

\begin{tabular}{|c|c|c|}
\hline Profession & Number & Percentage \\
\hline Liberal & 12 & 70,6 \\
\hline Student & 3 & 17,6 \\
\hline Military & 2 & 11,8 \\
\hline Total & 17 & 100 \\
\hline
\end{tabular}

The clinical examination consisted of a conserved general state, a good hemodynamic state and apyrexia in sixteen cases and a state of septic shock in one case at the entrance; a localized abdominal defense(periumbilical) in twelve cases and generalized in five cases at the entrance. With regards to cases of localized abdominal defense, the evolution was marked by a generalization of the abdominal pains after 6 hours in 9 patients and after 48 hours in 2 patients with association of the fever.

X-rays of the abdomen without preparation were carried out in 15 patients at the entrance which made it possible to show a pneumoperitoneum in 6 cases. The other two had benefited from an abdominal ultrasound showing an intraabdominal effusion, apart from a radiography of the abdomen without preparation. A patient had benefited from the outset at the entrance of an abdominal ultrasound that had revealed a rupture of the bladder. In addition, another patient had first had an abdominal ultrasound completed a CT scan demonstrating a peritoneal effusion without lesions of the intraabdominal full organs. Lastly, one patient had not received any imaging because he had presented with peritoneal irritation syndrome and septic shock at the entrance. The blood count was performed in all patients at the entrance and demonstrated hyperleukocytosis in 10 cases (in 5 patients with generalized abdominal defense). During surveillance the remaining seven patients had high leukocytosis. All patients had laparotomy. Indeed, the 5 patients who presented a generalized defense at the entrance had been operated within 6 hours following the trauma while among the remaining patients, eight had been operated within 24 hours, and two others after 72 hours. Bowels injuries observed were localized on jejunum (14 cases), the stomach (1 case), sigmoid (1case), and cecum (1case).

The main surgical gestures were: excision-suture jejunum in 13 cases; excision-suture the stomach in one case; resectionanastomosis of jejunum; peritonization of the sigmoid colon in one case and cecostomy in one case. Moreover, in the patient who presented a deperitonization of the sigmoid colon, there was a rupture of the associated bladder dome that required a cystography plus urinary catheter for 10 days. The outcome was marked by parietal suppuration in eight cases which had progressed well under local care. Two cases of incisional hernia were recorded, which were treated surgically and reinforced mechanically by placement of a mesh. We had three cases of death due to septic shock.

\section{Discussion}

Bowels injuries after abdominal blunt are infrequent in contrast to those of full intraabdominal organs. They represent 3 to $5 \%$ of abdominal injury after trauma $[1,2]$. They are often encountered in young male subjects because they are exposed to the phenomena of banditry, criminality, violence and indiscipline. They sit most often on the hail, but other parts of the digestive tract may also be interested. Thus, in order of frequency we have the small, stomach, colon, mesentery [1-4] as observed in our series.

Several mechanisms can explain the occurrence of intestinal lesions after

\section{Abdominal Trauma}

i. The crush rupture between an external body and the vertebral column;

ii. Bursting by tensioning of a viscera or segment of the viscera, even at a distance from

iii. the point of impact by the sudden increase in intraabdominal pressure;

iv. The stretching's or dilacerations of the hollow viscera, their mesentery by the sudden

v. deceleration resulting in hemorrhagic vascular lesions;

vi. The ischemia due to mesenteric lesions that may be revealed lately [2-5].

In clinical diagnosis, posttraumatic intestinal lesions are pauci-symptomatic at the beginning especially in the small intestine because of the digestive content which has an acid $\mathrm{pH}$ and little bacterial, explaining the least peritoneal irritation. On the other hand, later a confirmed peritonitis will settle with appearance of a generalized abdominal contracture. This has been the rule in most cases in our series. Abdominal skin lesions such as skin erosions and bruising are frequent but not specific, due to the violence of the trauma or the safety belt, must alert [27]. Sometimes the diagnosis is made only intraoperatively after abdominal trauma went unnoticed [6].

The contribution of imaging is undeniable in the diagnosis of posttraumatic intestinal lesions. The radiography of the abdomen without preparation can allow, inconsistently, to highlight a pneumoperitoneum. It does not often show pneumoperitoneum of minimal abundance [8]. It has been in six cases in our study. Massengo et al. [6] have reported only one case in their series. The abdominal ultrasound is a little sensitive because it does not show specific signs of intestinal perforation [7]. The CT scan is the gold standard to better explore posttraumatic bowel fractures. In fact, abdominal computed tomography can objectify the indirect signs in favor of an intestinal rupture: an 
intraperitoneal effusion without lesions of the intraabdominal full organs (which we noted in one of our patients); thickening of the intestinal walls and mesentery (inconstant); interruption of the intestinal wall in case of complete rupture (inconstant); pneumoperitoneum, of minimal abundance $[8,9]$.

Thus, in the absence of pneumoperitoneum in the CT scan, abdominal pain associated with hemodynamic effusion without full organ injury should suggest intestinal perforation until proven otherwise [9-11]. In this case an early exploratory laparotomy is recommended [12]. As a result, CT scans can be faulty or underestimate intestinal lesions in $25 \%$ of cases, as reported by several authors $[13,14]$. A delay in the management of traumatic digestive perforation is derogatory. Monitoring, repeated clinical examination or even CT scan are necessary in order to promptly indicate surgical exploration for hollow perforation.

Nowadays, with the development of endoscopy, exploratory laparoscopy can be of great help in the early diagnosis of posttraumatic intestinal lesions in case of doubt. It has a diagnostic and therapeutic interest that significantly reduces morbidity and mortality [8]. Nevertheless, it is indicated in cases of isolated abdominal contusion but constitutes an invasive means requiring a general anesthesia. It is contraindicated in case of hemodynamic instability and polytrauma as in this case it is associated with brain-encephalic traumas [8]. The surgical management of these intestinal lesions is a function of the intestinal segment reached, the period of diagnosis and the patient's condition. Early diagnosis and management are a guarantee of good outcome.

\section{Conclusion}

Post-traumatic intestinal lesions are infrequent, most often due to traffic accidents. The small Intestine particularly the jejunum is the most affected site. Diagnosis is often difficult and made late because of the poverty of the symptomatology at the beginning. However, monitoring, repeated clinical examination or even CT scan are necessary in order to provide a timely indication of surgical exploration for hollow organ perforation.

\section{References}

1. Baccoli A, Manconi AR, Caocci G, Pisu S (2010) Isolated jejunal perforation after blunt trauma. Report of three cases. G Chir 31(4): 167-170.

2. Sales JP (2002) Prise en charge des ruptures d'organes creux lors des traumatismes fermés de l'abdomen. Management of the Rupture of
Hollow Organs in the Closed Trauma of the Abdomen, MAPAR: 555563.

3. Traoré A, Dembélé BT, Diakité I, Togo A, Kanté L, et al. (2017) Traumatic Perforation of the Small Intestine in General Surgery of the CHU Gabriel Touré. Surgical Science 8: 414-421.

4. Geukens D, Danse E, Verschuren F, Kartheuser A, Mauel E, et al. (2005) Perforation sigmoïdienne traumatique : intérêt du bilan tomodensitométrique. Journal de radiologie 86(6): 663-665.

5. Sule AZ, Kidmas AT, Awani K, Uba F, Misauno M (2007) Gastrointestinal perforation following blunt abdominal trauma. East Afr Med J 84(9): 429-433.

6. Massengo R, Bikandou G, Mianfoutila S (1993) Rupture traumatiques du jejuno-iléon. A propos de 25 cas. Medecine d'Afrique Noire 40(3): 201-203.

7. Symeonidis N, Ballas $\mathrm{K}$, Psarras $\mathrm{K}$, Lalountas $\mathrm{M}$, Rafailidis $\mathrm{S}$, et al. (2010) Isolated Small Bowel Perforation After Blunt Abdominal Trauma: Report Of 2 Cases. The Internet Journal of Surgery 27(1).

8. Germain MA, Soukhni N, Bouzard MD (2003) Perforations du grêle par traumatisme fermé de l'abdomen évaluation par le scanner abdominal et la laparoscopie. Annales de chirurgie 128(4): 258-261.

9. Gay SB, Sistrom LC (1992) Computed tomographic evaluation of blunt abdominal trauma. Radiol Clin North Am 153: 747-753.

10. Hanssens F, Guaquiere C, Kara Terki N, Verhaeghe P (2001) Rupture traumatique du jéjunum non décelable par la tomodensitométrie hélicoïdale. Ann Chir 126: 457-486.

11. Ragot E, Bourillon C, Chevallier JC, Zinzindohoue F, Douard R, et al (2015) Perforation du tube digestif dans les traumatismes fermés de l'abdomen :signes cliniques et radiologiques. Journal de chirurgie viscérale 152(5) : A33.

12. Ng AK, Simons RK, Torreggiani WC, Ho SG, Kirkpatrick AW, et al. (2002) Intra-abdominal free fluid without solid organ injury in blunt abdominal trauma: an indication for laparotomy. J Trauma 52: 11341140.

13. Holmes JF, Offerman SR, Chang CH, Randel BE, Hahn DD, et al. (2004) Performance of helical computed tomography without oral contrast for the detection of gastrointestinal injuries. Ann Emerg Med 43(1): 120-128.

14. Brody JM, Leighton DB, Murphy BL, Abbott GF, Vaccaro JP, et al. (2000) CT of blunt trauma bowel and mesenteric injury: typical findings and pitfalls in diagnosis. Radiographics 20(6): 1525-1536. 

\begin{tabular}{l|l} 
(CC) & $\begin{array}{l}\text { This work is licensed under Creative } \\
\text { Commons Attribution 4.0 Licens } \\
\text { DOI: } 10.19080 / O A J S .2019 .10 .555786\end{array}$
\end{tabular}

\section{Your next submission with Juniper Publishers will reach you the below assets}

- Quality Editorial service

- Swift Peer Review

- Reprints availability

- E-prints Service

- Manuscript Podcast for convenient understanding

- Global attainment for your research

- Manuscript accessibility in different formats ( Pdf, E-pub, Full Text, Audio)

- Unceasing customer service

Track the below URL for one-step submission https://juniperpublishers.com/online-submission.php 